\title{
FIDEDIGNIDADE DE ATIVIDADES PARA O DESENVOLVIMENTO DA CAPACIDADE DE JOGO NOS ESPORTES COLETIVOS
}

\author{
Alex Rodrigues Teixeira \\ Universidade Federal de Ouro Preto, Ouro Preto, Minas Gerais, Brasil \\ Siomara Aparecida da Silva \\ Universidade Federal de Ouro Preto, Ouro Preto, Minas Gerais, Brasil
}

\begin{abstract}
Resumo
Como os conteúdos de ensino dos jogos esportivos são ensinados aos futuros professores de educação física? Analisando a concordância entre juízes sobre parâmetros do desenvolvimento da capacidade de jogo, pretendeu-se neste estudo identificar dificuldades no processo de ensino-aprendizagem. Cinco juízes avaliaram atividades indicando os parâmetros que a mesma objetivava desenvolver. Os resultados de concordância entre os juízes e dos mesmos com o gabarito demonstram maior dificuldade de identificar os parâmetros das capacidades táticas e certa facilidade para a coordenação motora. Aplicar uma proposta que organiza o processo de ensino ao longo dos anos requer conhecimento e dedicação para assegurar mudanças nos resultados.
\end{abstract}

Palavras-chave: Esportes. Educação Física e Treinamento. Teoria do Jogo.

\section{Introdução}

Como área de conhecimento, a Educação Física deve tratar das práticas corporais construídas ao longo dos tempos. Os jogos esportivos coletivos (JEC) sempre tiveram amplo espaço na realidade escolar, justificados principalmente pela aceitação dos alunos, a sua facilidade de aplicação e a estrutura física das escolas (COSTA; NASCIMENTO, 2004).

Os jogos esportivos coletivos são caracterizados por ações difíceis de serem avaliadas através de medidas no momento de sua realização. Essas ações podem ser entendidas como as habilidades básicas dos jogos esportivos no contexto do ensino. Nas modalidades de lançamentos e chutes as habilidades podem ser classificadas em transporte da bola (drible, condução) e acertar o alvo (lançamento ou arremesso e chute) (SILVA, 2010). 
Para Rochefort (1998), a formação do professor de Educação Física influencia a maneira como o esporte vem sendo ministrado nas escolas. Dessa forma, tanto os profissionais que atualmente estão nas escolas ensinando as modalidades coletivas como os que estão ainda em formação, poderiam estar preparados para, no mínimo, refletir acerca de novas abordagens no ensino dos esportes coletivos, tão necessários diante da realidade de ensino.

As diversas abordagens da Educação Física Escolar (EFE) no ensino dos jogos esportivos coletivos (JEC) como conteúdo da EFE apontam para um momento de reavaliar as metodologias de ensino dos mesmos. Os JEC são parte integrante da cultura escolar, promovendo benefícios físicos, psicológicos e sociais através de situações problema que servem de pilares didáticos pedagógicos para o professor. Entretanto, deve ser ensinado de forma estruturada para que seus conteúdos sejam prazerosos para o aluno ao longo dos anos escolares e que seja gratificante, respeitando a individualidade dos mesmos.

Dentre as propostas metodológicas para o ensino dos JEC, na considerada nova corrente, o método situacional que, segundo Kröger e Roth (2005), compõe-se de jogadas básicas extraídas de situações padrão de jogos tem seu conteúdo estabelecido em parâmetros para o ensino-aprendizagem-treinamento.

Os conteúdos sistematizados para o ensino dos JEC se adéquam a realidade da EFE no que tange a organização com direcionamento das faixas etárias, respeitando as características desenvolvimentais. $\mathrm{O}$ ensino fundamental I, dos seis aos onze anos, se equivale à etapa de formação. Esta se divide em três fases tendo como objetivo o desenvolvimento das habilidades fundamentais maduras, até os sete anos, sustentando a fase de combinação de habilidades fundamentais maduras, e servindo de base para a terceira e última fase em que o objetivo é a combinação das habilidades esportivas (GRECO; SILVA, 2008).

Na sequência, por volta dos 12 anos, na escola a criança estaria no ensino fundamental II e no processo de ensino-aprendizagem dos JEC na etapa de transição. Esta etapa com três subdivisões (Universal 3, orientação e direção) os conteúdos se propõem a desenvolver a universalidade esportiva, promovendo a aprendizagem de vários esportes, e direcionando as capacidades individuais às modalidades esportivas (GRECO; SILVA, 2008). 
A articulação entre os anos escolares e as idades de desenvolvimento da capacidade de jogo continua no ensino médio com o desencadear da tomada de decisão. Nesta etapa o adolescente decide o âmbito que o esporte ocupa na sua vida e a EFE apoia com conteúdos que sustentam o esporte de lazer, de saúde e qualidade de vida e, até quem sabe, o esporte de rendimento da escola, expressando-se como fruto do longo processo de ensino-aprendizado.

A Aprendizagem Tática é composta pelas Estruturas Funcionais (EF), Capacidades Táticas Básicas (CTB) e Jogos para o Desenvolvimento da Inteligência e Criatividade (JDIC). A Aprendizagem Motora é composta pelas Capacidades Coordenativas e Habilidades Técnicas (GRECO; BENDA, 1998).

Segundo Kröger e Roth (2002), os parâmetros das Capacidades Coordenativas (Tempo, Precisão, Sequência, Organização, Variabilidade e Carga), os parâmetros das capacidades táticas básicas (Acertar o alvo, Transportar a bola ao objetivo, Jogo coletivo, Reconhecer espaços, Superar o adversário, Tirar vantagem tática no jogo, Oferecerse e orientar-se), os parâmetros das habilidades técnicas (Controle dos ângulos, Regulação de aplicação da força, Determinar o momento do passe, Determinar linhas de corrida e tempo de bola, Oferecer-se, Antecipar a direção do passe, Antecipação defensiva, Observação dos deslocamentos), são típicos nos JEC, considerados "tijolos" necessários para a construção dos conceitos táticos e técnicos dos jogos esportivos coletivos, por parte das crianças e adolescentes.

A necessidade de contrapor à "tradição" à "inovação" requer dos profissionais um pensamento crítico e reflexivo que exige esforço, dedicação e formação continuada (COSTA; NASCIMENTO, 2004). Pensar no futuro professor é proporcionar práticas docentes que apresentem propostas metodológicas de ensino dos esportes que proporcionem a este escolhas, caminhos do como e o que ensinar.

Dessa forma, por meio da preocupação dos docentes em proporcionar o conhecimento e a reflexão acerca de novas abordagens de ensino na formação inicial e de algumas alterações curriculares, poder-se-ia vislumbrar uma mudança gradual no ensino, em especial na metodologia dos esportes coletivos, buscando assim o ensino da técnica e tática numa perspectiva de construção de experiências e vivências gratificantes para o aluno (COSTA; NASCIMENTO, 2004) e para a sociedade como um todo. 
Independente da modalidade é importante ressaltar que nos jogos esportivos coletivos a elaboração do processo de ensino-aprendizagem deve ser formulada cuidadosamente, o que solicita do professor o conhecimento das diferentes alternativas metodológicas. Torna-se, assim, fundamental oportunizar processos de ensino-aprendizagem que promovam o desenvolvimento das potencialidades e competências dos alunos, respeitando suas diferenças individuais e promovendo um crescimento amplo e diversificado nas suas capacidades, fomentando sua integração e enriquecimento da sua personalidade.

Confiar nos conteúdos de ensino dos jogos para desenvolver uma metodologia de ensino que apresente a fidedignidade e aplicabilidade de atividades sistematizadas, proporcionando aos professores atividades que realmente desenvolvam as capacidades coordenativas, habilidades técnicas e capacidades táticas básicas, sendo que estas atividades podem sofrer variações de acordo com as faixas etárias e necessidades dos alunos diminuindo ou aumentando o grau de complexidade.

O profissional de Educação Física deve valorizar seu espaço de trabalho, planejando cuidadosamente suas atividades para que elas criem oportunidades ao desenvolvimento de competências pessoais, sociais, produtivas e cognitivas de seus alunos. Cabe ao professor fazer com que a educação pelo esporte aconteça na prática, não como a pura repetição de uma receita que dá certo, mas como um campo enorme de novas experimentações e descobertas, criadas a partir da incorporação ao processo educativo de suas qualidades como educador e como pessoa.

A importância de atividades fidedignas para o desenvolvimento das capacidades coordenativas, capacidades táticas básicas e habilidades técnicas no contexto dos jogos esportivos são meios do que ensinar em cada faixa etária respeitando a especificidade e proporcionando o desenvolvimento integral dos alunos. Contudo o professor precisa conhecer as propostas de ensino-aprendizagem, ter a capacidade de sair da teoria para prática, propondo novas atividades.

O objetivo deste estudo foi analisar a concordância entre os juízes dos parâmetros de atividades para o desenvolvimento da capacidade de jogo nos esportes coletivos e discutir suas implicações. 


\section{Metodologia}

Os procedimentos éticos de aplicação do projeto e o termo de consentimento livre esclarecido (TCLE) foram aprovados pelo Comitê de Ética em Pesquisa da Universidade Federal de Ouro Preto (UFOP) com o protocolo CAAE: 0049.0.238.000-11.

Os juízes da área da Educação Física foram selecionados por serem alunos participantes do Grupo de Estudo das Capacidades de Rendimento dos Esportes Coletivos (GECREC), monitores do Programa Segundo Tempo Padrão da Universidade Federal de Ouro Preto (PST-P - UFOP) e por contínuo acompanhamento pedagógico teórico e prático com professores que dominam a proposta teórica, possibilitando aos mesmos conhecimentos sobre a proposta aplicada. Eles receberam uma carta convite por e-mail e da mesma forma receberam o material para avaliarem o quanto as atividades propostas referem-se à aprendizagem tática e aprendizagem motora.

Foram convidados 10 juízes, mas contou-se com a colaboração de 05 juízes. Os juízes demonstraram sua opinião utilizando um questionário, no qual foram fornecidas as atividades enumeradas em ordem crescente, nas quais os juízes expressavam sua opinião através do parâmetro correspondente a atividade de aprendizagem motora e aprendizagem tática.

$\mathrm{Na}$ aprendizagem tática foram elaboradas 22 atividades de Capacidades Táticas Básicas (CTB). Na aprendizagem motora foram elaboradas 20 atividades de Capacidades Coordenativas (CC) e 20 atividades de Habilidades Técnicas (HT).

\section{Descrição da análise}

As respostas dos juízes foram digitadas em uma planilha Microsoft Office Excel 2007. Posteriormente analisadas por porcentagem (\%) de concordância interna. A porcentagem foi graduada em 100\% - concordância entre todos os juízes; $80 \%$ - concordância entre quatro juízes; $60 \%$ - concordância entre três juízes; $40 \%$ abaixo não houve concordância entre os juízes.

A concordância acima de $80 \%$ foi comparada com um gabarito. Foram considerados como gabarito os parâmetros apresentados no livro fundamentos pedagógicos para o programa segundo tempo (OLIVEIRA; PERIM, 2008). Em algumas atividades havia mais de um 
parâmetro, mas apenas o primeiro condicionante foi acatado.

\section{Resultados}

Neste estudo foi realizada uma comparação da concordância da maior porcentagem (\%) das repostas internamente entre os juízes e o gabarito. Os dados são apresentados na tabela 1.

Tabela 1 - Média de concordância com o gabarito (CG) e entre Juízes (EJ)

\begin{tabular}{cccc}
\hline & $\begin{array}{c}\text { Capacidades } \\
\text { Coordenativas }\end{array}$ & $\begin{array}{c}\text { Capacidades } \\
\text { Táticas Básicas }\end{array}$ & $\begin{array}{c}\text { Habilidades } \\
\text { Téenicas }\end{array}$ \\
\hline $\begin{array}{c}\text { Média de } \\
\begin{array}{c}\text { Concordância com } \\
\text { o Gabarito }\end{array}\end{array}$ & 56 & 21,8 & 45 \\
$\begin{array}{c}\text { Média de } \\
\begin{array}{c}\text { concordância entre } \\
\text { os Juizes }\end{array}\end{array}$ & 75 & 66,4 & \\
\hline
\end{tabular}

Considerando a média de concordância com o gabarito pode-se observar que as CC, CTB e HT apresentaram níveis de concordância inferiores a 60 , por outro lado as mesmas apresentaram níveis de concordância superiores a 60 quando comparadas entre os juízes.

Também foi realizada uma comparação de concordância das repostas dos juízes com o gabarito e internamente entre os juízes considerando uma escala de $\leq 40 \%$ e $\geq 80 \%$. Os dados são apresentados na tabela 2 .

Tabela 2 - Relação do número de atividades com grau de concordância $\leq 40 \% \mathrm{e} \geq$ $80 \%$ com o gabarito (CG) e entre os juízes (EJ).

\begin{tabular}{ccccc}
\hline & & $\begin{array}{c}\text { Capacidades } \\
\text { Coordenativas }\end{array}$ & $\begin{array}{c}\text { Capacidades } \\
\text { Táticas Básicas }\end{array}$ & $\begin{array}{c}\text { Habilidades } \\
\text { Técnicas }\end{array}$ \\
\hline $\mathrm{N}^{\circ}$ de atividades & & 20 & 22 & 20 \\
& CG & 08 & 18 & 09 \\
$\leq 40 \%$ & EJ & 01 & 04 & 02 \\
& CG & 08 & 03 & 08 \\
$\geq 80 \%$ & EJ & 10 & 07 & 11 \\
\hline
\end{tabular}

Em relação às Capacidades Coordenativas (CC) observa-se que 10 das 20 atividades analisadas pelos juízes apresentam um nível de concordância interna (EJ) maior ou igual a 80\%, sendo que, 06 atividades apresentaram $100 \%$ de concordância entre eles. Considerando a concordância dos juízes com o gabarito (CG) observa-se que 08 ativi- 
dades apresentaram concordância maior ou igual a 80\%, sendo que 06 atividades apresentaram $100 \%$ de concordância com o gabarito.

As Capacidades Táticas Básicas (CTB) apresentaram 07 e 03 atividades com um nível de concordância entre os juízes (EJ) e com o gabarito maior ou igual a $80 \%$ respectivamente. Sendo que, 04 e 03 atividades apresentaram um nível de concordância entre os juízes (EJ) e com o gabarito igual a $100 \%$.

Entre as 22 atividades de CTB, as respostas de 18 atividades analisadas com o gabarito (CG) apresentaram nível de concordância $\leq$ $40 \%$, sendo que 13 destas não apresentaram concordância, e em 04 atividades as respostas entre os juízes (EJ) foram abaixo de $40 \%$ de concordância.

As atividades de Habilidades Técnicas (HT) apresentaram os maiores valores de concordância entre os juízes (EJ) e com o gabarito, 11 e 08 atividades com concordância $\geq 80 \%$, respectivamente. Sendo que, uma atividade apresentou $100 \%$ de concordância entre os juízes e com o gabarito.

Por outro lado, 09 e 02 atividades apresentaram um nível de concordância com o gabarito (CG) e entre os juízes (EJ) menores ou iguais a $40 \%$ respectivamente, sendo que, 06 atividades apresentaram um nível de concordância igual a zero quando comparadas ao gabarito.

Neste estudo também foi calculada a consistência interna entre os juízes através da técnica do Alfa de Cronbach que apresentou um valor de $\alpha=0,38$. O cálculo do coeficiente alfa permite estimar até que ponto cada item da escala mede de forma equivalente o mesmo conceito.

\section{Discussão}

As CC e HT apresentaram valores superiores de concordância entre os juízes e com o gabarito o que pode estar relacionado à construção metodológica histórica do ensino da Educação Física, que tem o ensino das técnicas das modalidades esportivas, conhecidos como o método analítico ou parcial. Segundo Greco (2001) este método se caracteriza por apresentar sequência de exercícios em que os elementos técnicos são oferecidos através de séries e formas rudimentares da modalidade esportiva. 
Os atributos do método analítico que caracterizam a abordagem tecnicista compuseram as experiências dos acadêmicos de Educação Física do grupo de juízes. O vivenciado na prática na educação básica pode ter influenciado na facilidade de identificação dos parâmetros das CC e HT no contexto de ensino-aprendizagem.

Segundo Rosário e Darido (2005), é complicado romper com uma perspectiva esportivista quando um professor teve aulas predominantemente esportivistas quando criança. Esse fator é reforçado quando durante a graduação ainda encontra uma formação profissional esportivista, ou pelo menos alguns resquícios dela. Essa reação em cadeia culmina quando o acadêmico vai trabalhar na escola com a visão centrada nos esportes, ainda mais quando seus alunos esperam aprender apenas esportes. Daí cria-se um ciclo (DARIDO, 2003).

As Capacidades Coordenativas (CC) apresentaram a maior média de concordância entre os juízes. Fato este que pode estar relacionado à influência dos conhecimentos desenvolvidos no grupo de estudo que os juízes frequentam. O grupo (GECREC) estuda capacidades de rendimentos dos esportes coletivos predominantemente a coordenação motora. Além disso, ou por causa disto, os parâmetros da coordenação motora são mais fáceis de serem identificados nas atividades por serem isolados, fora de uma situacionalidade.

As atividades de HT analisadas pelos juízes apresentam os maiores níveis de concordância interna (EJ), $\geq 80 \%$, fato que pode estar relacionado à influência do método parcial ou analítico. Weineck (1999) coloca que esse método é utilizado no treinamento de movimentos complexos que serão executados em partes e articulados quando forem dominados. Os parâmetros das Habilidades Técnicas são vistos como componentes necessários para o posterior treinamento da técnica. Assim, Kröger e Roth (2002) os denominam de "tijolos" presentes em todas as técnicas sustentadas pela $\mathrm{CC}$ e que estão presentes nas diferentes modalidades dos JEC.

Em um estudo realizado por Rosário e Darido (2005) sobre a sistematização dos conteúdos da educação física na escola identificou-se que professores de Educação Física têm restringido seu trabalho aos esportes tradicionais, que são transmitidos superficialmente, e em geral distribuídos sem nenhuma sistematização. Quando a fazem, os professores dispõem os conteúdos ao longo do ano através dos bimestres, com um esporte coletivo como conteúdo principal, e outros conteúdos dispostos paralelamente durante o ano, no caso, os jogos e 
outros esportes, mas não há mudanças ao longo do ciclo de escolaridade.

Um estudo realizado por Gueriero e Araújo (2004) identificou que a educação física escolar tende a apresentar uma esportivização de seus conteúdos em algumas séries do ensino fundamental. A pesquisa constitui-se em observações de aulas de turmas de sétima e oitava séries do ensino fundamental, que verificou que $54,1 \%$ das aulas observadas apresentaram conteúdo esportivo tradicional.

Outro estudo realizado por Pereira e Silva (2004) que corrobora com este achado, os autores estudaram os conteúdos de Educação Física do Ensino Médio do RS nas redes federal, estadual e privada através de análises documentais e entrevistas com 22 professores de 18 instituições, em seis diferentes cidades. Dos 2.289 conteúdos analisados, os esportivos compreenderam $66,9 \%$ contribuindo para a supremacia e hegemonia do esporte dentro do contexto escolar.

Neste estudo procurou-se abordar a sistematização dos parâmetros de ensino dos JEC, conteúdo da Educação Física escolar, analisando os parâmetros da aprendizagem motora e aprendizagem tática.

As CTB apresentaram um nível de concordância entre os juízes e em relação ao gabarito muito baixo. Um fator que pode ter influenciado esse baixo nível nas respostas dos juízes se deve ao fato de que muitas das atividades analisadas apresentam mais de um parâmetro como objetivo da atividade. O fato pode ter causado confusão na análise do parâmetro principal que a atividade propunha a desenvolver.

A pouca vivência com os parâmetros de ensino dos JEC pesquisados dificulta a identificação dos parâmetros das CTB. Como já discutido anteriormente a vivência dos acadêmicos no processo de aprendizagem da técnica ao longo da formação básica pode ter influenciado na identificação dos parâmetros das CTB. O ensino dos jogos através do método global, segundo Mesquita (2000), apresenta durante o treinamento uma situação de jogo na qual os elementos técnicos e táticos são vivenciados juntos. Muitas vezes as CTB são confundidas com complexos de jogos, os quais estão mais relacionados às estruturas funcionais do que CTB. Neste estudo as estruturas funcionais não foram analisadas, apesar de fazerem parte da proposta de ensino dos jogos coletivos (GRECO; SILVA; SANTOS, 2009).

Em um estudo realizado por Costa e Nascimento (2004) identificou-se que diferentes investigações sobre a prática pedagógica de 
professores de Educação Física têm revelado o predomínio da abordagem tradicional no ensino dos esportes. Em contrapartida com a tendência centrada na técnica, surgiu a preocupação com o processo de ensino da tática nos esportes, no sentido de assegurar que o aluno aprenda a tomar decisões e resolver problemas que ocorrem durante $\mathrm{o}$ jogo. As novas tendências metodológicas preocupam-se com a articulação do ensino da técnica e tática, nomeadamente as metodologias baseadas nas estruturas funcionais, no ensino para a compreensão e no modelo desenvolvimentista.

Pesquisas têm avaliado o desenvolvimento da capacidade tática nos jogos esportivos coletivos. Mesquita et al. (2005) analisaram a contribuição de 12 sessões de treinamento de voleibol com base no ensino a partir de uma abordagem tática. Através das análises de vídeos de situações de jogo de 2 contra 2, de escolares de ambos os sexos, com idade entre 12 e 15 anos, foi verificada evolução de parâmetros táticos, como tomada de decisão no ataque, ajustes durante a recepção e o desempenho tático geral.

Costa et al. (2007) verificaram como tem sido realizado o processo de ensino-aprendizagem-treinamento no voleibol e se esse processo favorece o desenvolvimento do conhecimento tático das jogadoras. Analisando a estrutura de treinamento a partir das filmagens realizadas, houve distribuição semelhante do tempo destinado às atividades com finalidade de desenvolvimento técnico $(42,8 \%)$ e tático $(44,3 \%)$, sendo o restante do tempo dedicado ao treinamento do jogo formal, ou seja, complexo de jogo coletivo.

Neste mesmo estudo foi possível identificar que o método de ensino-aprendizagem-treinamento utilizado pelo treinador não demonstrou ser centrado apenas no aperfeiçoamento técnico, visto que em boa parte do tempo total de treinamento - aproximadamente $45 \%$ - foram aplicadas atividades consideradas no quesito complexo de jogo, que visam principalmente o aprimoramento tático da equipe.

Esses dados corroboram com este estudo destacando a importância de desenvolver os parâmetros das capacidades táticas básicas nas aulas de educação física. As CTB fazem parte de uma nova corrente metodológica, o método situacional (GRECO; BENDA, 1998) que segundo Kröger e Roth (2005) compõe-se de jogadas básicas extraídas de situações padrão de jogo. Elas podem, às vezes, não abranger a ideia total do jogo, porém tais situações possuem o elemento central do jogo, desenvolvendo a tomada de decisão que pode ser utilizada 
em outras situações de jogo. Para estes autores as crianças devem adquirir uma capacidade geral do jogo e competência tática.

No que tange a validação de instrumentos, Silva (2010) propondo uma bateria de testes para medir a coordenação com bola nos JEC analisou a validade de conteúdo através da análise de juízes. Nas dimensões de clareza de linguagem, relevância ecológica e representatividade os resultados indicaram coeficientes de validade superiores a $\alpha=0,80$.

Valentini et al. (2008) validando o TGMD-2 (Test of gross motor development) verificou a validade de conteúdo da versão em português com critérios motores claros e pertinentes na análise dos juízes.

Neste estudo foi realizada uma análise da concordância entre os juízes com o objetivo de identificar atividades que realmente desenvolvem o que se propõem a desenvolver. Atividades fidedignas para o desenvolvimento dos parâmetros da aprendizagem motora e aprendizagem tática no contexto dos jogos esportivos são meios para orientar a práxis pedagógica do professor contribuindo para uma melhor organização e sistematização das aulas de Educação Física dentro do contexto escolar.

\section{Considerações finais}

Os resultados apresentados demonstram a dificuldade de identificar um parâmetro da proposta de ensino da capacidade de jogo, contida na Iniciação Esportiva Universal (IEU) por pouco conhecimento da mesma e influência das vivências anteriores dos acadêmicos. Retratamos a importância dos professores conhecerem novas abordagens metodológicas de ensino dos JEC para que seus conteúdos sejam desenvolvidos numa perspectiva de construção de experiências.

Torna-se necessário que o professor de Educação Física Escolar tenha conhecimento e entendimento de atividades que realmente desenvolvam capacidades e habilidades motoras para que possa organizar a sua prática pedagógica e que os conteúdos esportivos efetivados possam favorecer o processo ensino-aprendizagem. O professor deve criar variações nas atividades de forma que favoreça a situacionalidade dos jogos esportivos coletivos dentro do contexto escolar, possibilitando um processo mais rico e prazeroso para o aprendiz e para o próprio professor. 


\title{
Reliability in activities for the development of playing abilities in team sports
}

\begin{abstract}
How are the sports games teaching contents taught to future physical education teachers? Analyzing the judges's correlation about the development parameters of playing ability, this study aimed to identify difficulties in the teaching-learning process. Five judges evaluated activities indicating the parameters that it aimed to develop. The judges and the evaluators correlation results show that there's a certain difficulty in identifying the tactical capabilities parameters, and relative ease in identifying motor coordination. Applying a proposal to organize the teaching process over the years requires knowledge and dedication to ensure changes in the results.
\end{abstract}

Keywords: Sports. Phisical Education and Training. Game Theory.

Fiduciario para el Desarrollo de Capacidades en el Juego de Deportes Colectivos

\section{Resumen}

Como los contenidos de enseñanza de los deportes se les enseña a los futuros profesores de educación física? El análisis de la correlación entre los parámetros de los jueces en el desarrollo de la capacidad de jugar, este estudio tuvo como objetivo identificar las dificultades en el proceso de enseñanza-aprendizaje. Cinco jueces evaluaron las actividades que indican los parámetros que se querían desarrollar. Los resultados de acuerdo entre los jueces y lo mismo con sus comentarios muestran una mayor dificultad en la identificación de los parámetros de la relativa facilidad ycapacidad táctica de la coordinación. Aplicar una propuesta para organizar el proceso de enseñanza en los últimos años requiere conocimiento y dedicación para garantizarlos cambios en los resultados.

Palabras clave: Deportes. Educación y Entrenamiento Físico. Teoria del Juego.

\section{Referências}

COSTA, H. C. M. et al. Efeito do processo de treinamento técnico-tático no nível de conhecimento declarativo de jovens praticantes de voleibol. Revista Mineira de Educação Física, Viçosa, v.15, n.2, p.519, 2007.

COSTA, L. C. A.; NASCIMENTO, J. V. O ensino da técnica e da tática: novas abordagens metodológicas. Revista da Educação Física/UEM, Maringá, v. 15, n. 2, p. 49-56, jul./dez., 2004.

DARIDO, S. C. Educação Física na Escola: questões e reflexões. Rio de Janeiro: Guanabara Koogan, 2003. 
GARGANTA, J. Para uma teoria dos Jogos Desportivos Colectivos. In: GRAÇA, A.; OLIVEIRA, J. (Eds.). O ensino dos Jogos Desportivos. Porto: CEJD/FCDEF-UP, 1995. p. 11-25

GUERIERO, D. A; ARAÚJO, P. F. Educação Física escolar ou esportivização escolar?. Revista digital. Efdeportes, Buenos Aires, v. 10, n. 78, n. p., nov. 2004.

GRECO, P. J. Métodos de ensino-aprendizagem-treinamento nos jogos esportivos coletivos. In: GARCIA, E. S. ; LEMOS, K. L. M. (Org.). Temas atuais VI em Educação Física e esportes. Belo Horizonte: Health, p. 48-72. 2001.

GRECO, P. J; BENDA, R. N. Iniciação Esportiva Universal. Da aprendizagem motora ao treinamento técnico. Belo Horizonte: Ed. UFMG, 1998.

GRECO, P. J. et al. Aprender a jogar handebol jogando, jogar para aprender. In: BRASIL. Ministério do Esporte. Comissão de Especialistas de Educação Física (Ed.).: Manifestações dos Esportes: Esporte escolar - Curso de Especialização. v. 5. Brasília: Universidade de Brasília CEAD, 2005. p.140-171.

GRECO, P. J; SILVA, S. A. A metodologia de ensino dos esportes no marco do programa segundo tempo. In: OLIVEIRA, A. A. B.; PERIM, G. L. Fundamentos pedagógicos para o programa segundo tempo. Porto Alegre: UFRGS, 2008.

GRECO, P. J; SILVA, S. A; SANTOS, L. R. Organização e desenvolvimento pedagógico do esporte no programa segundo tempo. In: OLIVEIRA, A. A. B.; PERIM, G. L. Fundamentos pedagógicos para o programa segundo tempo: da reflexão à prática. Maringá: UEM, 2009.

KRÖGER, C; ROTH, K. Escola da Bola: Um ABC para iniciantes nos jogos esportivos. São Paulo: Phorte, 2002. . 2 ed. São Paulo: Phorte, 2005.

MESQUITA, I. Modelação no treino das habilidades técnicas nos jogos desportivos. In: GARGANTA, J. (Ed.). Horizonte e órbitas no 
treino dos jogos desportivos. Porto: Converge Artes Gráficas, 2000. p. 73-89.

MESQUITA, I. et al. Examining the impact of a step game approach to teaching volleyball on student tactical decision making and skill execution during game play. Journal of Human Movement Studies, v. 48, n. 6, p. 469-492, 2005.

OLIVEIRA, A. A. B; PERIM, G. L. Fundamentos pedagógicos para o programa segundo tempo. Brasília: Ministério dos Esportes, 2008.

PEREIRA, F. M; SILVA, A. C. Sobre os conteúdos da educação física no ensino médio em diferentes redes educacionais do Rio Grande do Sul. Revista da educação física/UEM, Maringá, v. 15, n. 2, p. 67-77, jul./dez., 2004.

ROCHEFORT, R. S. Voleibol: das questões pedagógicas a técnica e tática do jogo. Pelotas: Universitária, 1998.

ROSÁRIO, L. F. R; DARIDO, S. C. A sistematização dos conteúdos da educação física na escola: a perspectiva dos professores experientes. Motriz, Rio Claro, v.11, n. 3, p. 167-178, set/dez., 2005.

SILVA, S. A. Bateria de testes para medir a coordenação com bola de crianças e jovens. 2010. $154 \mathrm{f}$. Tese (Doutorado em Ciências do Movimento Humano)-Escola de educação física, Universidade Federal do Rio Grande do Sul, Porto Alegre, 2010.

VALENTINI, N. C. et al. Teste de Desenvolvimento Motor Grosso: Validade e consistência interna para uma população Gaúcha. Revista Brasileira de Cineantropometria \& Desempenho Humano, Florianópolis, v. 10, n. 4, p.399-404, out./dez., 2008.

WEINECK, J. Treinamento ideal: instruções técnicas sobre o desempenho fisiológico, incluindo considerações específicas de treinamento infantil e juvenil. São Paulo: Manole, 1999.

Recebido em: 16/07/2012

Revisado em: 21/11/2012

Aprovado em: 08/01/2013

Pensar a Prática, Goiânia, v. 16, n. 3, p. 619-955, jul./set. 2013 


\section{Endereço para correspondência}

alexrtcanaa@yahoo.com.br

Alex Rodrigues Teixeira

Centro Desportivo da Universidade Federal de Ouro Preto (CEDUFOP)

Campus Morro do Cruzeiro s/n - Bairro Bauxita

Ouro Preto - Minas Gerais - CEP - 35400-000 